Joicy Silva Ferreira, Federal University of Minas Gerais, Brazil

Miriam de Paiva Vieira, Federal University of São João del Rei, Brazil

DOI: 10.17951/Ismll.2020.44.2.51-62

\title{
From Brushes to Lenses: An Ekphrastic Stroll in A Line Made by Walking by Sara Baume
}

\begin{abstract}
There is a sizeable body of scholarship concerning the ekphrastic relation of literature to painting - however, there has been ascending interest in other sources of inspiration, such as photography. The aim of this paper is to explore whether the categories used to analyse ekphraseis of paintings might apply to the ekphraseis inspired by photography in Sara Baume's A Line Made by Walking (2017), considering that they provide insightful information regarding the creative process of the protagonist and her inner state. The notion of ekphrasis (Clüver, Vieira, Webb) and theories of photography (Barthes, Machado, Sontag) will be used as theoretical support.

Keywords: ekphrasis, photography, painting, intermediality, comparative literature, Sara Baum
\end{abstract}

\section{Introduction}

In times of voluntary isolation, the story ofFrankie, an artist in her mid-twenties who succumbs to a nervous breakdown and moves into her grandmother's bungalow in the Irish countryside, is likely to promote insights of different ways to make the absent present. We propose to examine how Frankie, the protagonist of the novel A Line Made by Walking (2017), by the Irish artist and author Sara Baume, copes with her confinement by embarking on a photographic project that happens to be revealed by means of ekphrastic passages. Departing from the understanding of photography's intrinsic features along with categories previously proposed for the study of ekphrasis of paintings, we will reflect upon the similarities and differences promoted by ekphraseis ${ }^{1}$ inspired by the protagonist's photographic project composed of a series of animal corpses found in her secluded surroundings. Frankie's venture is guided by two self-imposed principles: firstly, the depicted

1 Regarding the plural form of ekphrasis, although dictionaries of general English accepts its spelling as ekphrases, we chose to follow the form used by our theoretical scope: ekphraseis.

Joicy Silva Ferreira, Faculdade de Letras, Universidade Federal de Minas Gerais, Av. Antônio Carlos, 6627, Pampulha. Belo Horizonte/MG. CEP 31270-901, joy.silvaferreira@gmail.com,

https://orcid.org/0000-0003-2427-5853

Miriam de Paiva Vieira, Departmento de Letras, Artes e Cultura, Universidade Federal de São João del Rei. Campus Dom Bosco. Praça Dom Helvécio, 74, Fábricas. São João del Rei/MG, CEP 36301-160, miriamvieira@gmail.com, https://orcid.org/0000-0001-9851-0217 
animals must already be dead; and, secondly, no pets are to be included. For doing so, we count on theories of photography (Barthes, Machado, Sontag) and the notion of ekphrasis (Clüver, Vieira, Webb).

\section{Creating visual and verbal images}

Photography has been connected since its first invention to the visual arts and especially to painting. The photography theoretician Arlindo Machado $^{2}$ (2015) explains that the invention of the camera dates back to the Renaissance, when devices built using the principle of the camera obscura first gained popularity among painters ${ }^{3}$. These early devices, consisting of a sealed black box with a single hole allowing the entry of a shaft of light, enabled a perfectly mimetic (albeit inverted) reproduction of the visible world: often, a tableau of objects arranged and lit by the painter. At this early stage, however, the projected image still required the artist's brush in order to be fixed. Machado also states that the invention of photography represented the crossing of two different discoveries in time and space: the camera obscura and Leon Battisti Alberti's Perspectiva Artificialis, explored in his 1443 Della Pictura. Intended to represent tridimensional relations within a bidimensional plan, Alberti's system of geometric projections improved the definition of images generated by the camera obscura. After the Renaissance, technology evolved beyond painting enabling discoveries that no longer depended on human mediation for the process of fixing images, such as the light-sensitivity of silver and its compounds. So, with the right chemical materials, the device itself could fix the image to its film.

This chemical process of capturing and fixing an image of one instant from a moment in life is at the root of a common superstition regarding photography: namely, that the camera might somehow steal the subject's soul, confining it within the final photograph. Machado (2015) explains how "some people commonly considered 'primitive' had the belief that photography could steal their spirits, and they refused to be photographed, fearing that a part of themselves would be fixed in the celluloid"4 (p. 39). This popular belief is reflected in Honoré de Balzac's rather fanciful theory that all physical bodies are covered with an infinite number of spectral layers, and that each time a person is photographed, one of these layers is transferred to the film (p. 39).

As media technology, photography's historical background is relevant here due to the attention drawn to the device's mechanical nature and its ability to effectively

2 Theoretician Arlindo Machado (1949-...) is a photography curator, critic and professor at the School of Communication and Arts, University of São Paulo. He is one of the main experts in his field in Brazil.

3 For more detailed information, see Machado (2015) and Fainguelernt (2014).

4 Original text: "Alguns povos ditos 'primitivos' acreditam que a fotografia lhes rouba o espírito e resistem em ser fotografados, temendo que alguma parte de si seja fixada no celuloide" (Machado, 2015, p. 39). Unless otherwise stated, all translations are our own. 
capture reality. In 1984's Camera Lucida, Barthes posits that photography never distinguishes itself from its referent, and that the presence of the photographed subject/object is also never metaphorical, given that the photo is the reflection of its luminous emanation. Conversely, Sontag (1977) had suggested how photography is not merely an image or interpretation of reality: it is a derivative of reality. According to her, "a photograph is never less than the registering of an emanation (light waves reflected by objects) - a material vestige of its subject in a way that no painting can be" (p. 120). Krauss (1977), when discussing Charles Peirce's notion of the index, recalls his statement that photographs' stronger, more immediate connection to reality stems from their "having been produced under such circumstances that they were physically forced to correspond point by point to nature" (p. 63). And this matter of indexically happens to be the reason Barthes had previously called photography a certificate of presence. Machado (2015), in his turn, criticizes this direct association of photography with reality - a standpoint he refers to as realism. To him, this argument ignores the fact that when the luminous information enters the camera, "it allows itself to be restructured to comply with the convention of the pictorial system"s (p. 47), and that the refracted luminous information is later converted to the material basis of the film. Therefore, this argument dismisses the transformations suffered by the luminous information before achieving the final image processed into the photonegative. Nevertheless, Machado argues that photography cannot in fact be considered a pure register of an immanence of the object, since it creates a reality that only exists within itself. By agreeing with Barthes that photography cannot exist without its referent, Machado adds that it depends just as strongly on its mechanical support, i.e., the photographic device. While his opinion regarding the connection between photography and reality is slightly different from that of the other theorists mentioned thus far, his discussion of photography's evolution, as well as its relation to paintings, contribute to the question at the centre of this study: how do ekphraseis inspired by photography resemble those inspired by paintings? How do they differ?

The concept of ekphrasis comes from the ancient rhetorical device used to make something that is absent present in the mind of an audience, in such a vivid way that it helps maintain history and culture alive (Webb, 2009, p. 26). Since the nineteenth century and the advent of widespread technical reproducibility, history no longer depended on people's memory to survive; hence, the role of ekphrasis has changed (Vieira, 2017, p. 51-54). In the contemporary field of Intermedial Studies, it is considered a relevant (trans)medial phenomenon by models proposed to the study of media transformation, as the ones suggested by Rajewsky (2005) and Elleström (2010).

5 Original text: "se deixa reestruturar para conformar-se à convenção de um sistema pictórico" (Machado, 2015, p. 47). 
The well-accepted contemporary definition of ekphrasis proposed by Heffernan (1993) - "the verbal representation of a visual representation" (p. 3) was revisited by Clüver in 1997 and updated in his latest article on the topic as the "representation of real or fictive configurations composed in a non-kinetic visual medium" (Clüver, 2016, p. 462). Clüver deems it relevant that ekphrasis preserves the ancient premise of evoking a vivid image in the reader's mind. Besides evident compositional resemblances, in order to achieve this vivid effect, certain intrinsic features of the source medium (in this case, photography) are likely to be enhanced by ekphrastic passages.

In order to better understand what characterizes an ekphrasis inspired by photography, it is necessary to understand its intrinsic features, or "media modes" in the words of Elleström (2010). These features force us to "recognize the 'affordances' of any communicative relation" (Bruhn, 2016, p. 18). The modes of photography include both the mechanical device used to capture images (which might be a professional camera, a smartphone, or even a tablet) and the different accessories that go along with it, from lenses on cameras to digital configurations and filters on smartphones. The material on which the photos are printed (if they are printed at all), whether upscale photographic paper or simply regular stock, should also be taken into account. As explained by Machado, many nuances of colour will be determined by these factors. He singles out three aspects of the process of developing film ${ }^{6}$ that will strongly affect the final image: the ink's materiality, the range of shades produced by the silver grains, and the artist's motivation (Machado, 2015, p. 165). Photography also brings into play other intrinsic features: the framing, point of view, and perspective adopted by the photographer, as well as the possibility of the photographs being manipulated, and the fact that the original could be enlarged or reduced when printed in different scales. Some of the unique specificities of photography include the possibility of arrested motion and, especially in current digital photography, the prospect of endless duplication and dissemination. Here the "technical reproduction" envisaged by Benjamin (1936) in his ground-breaking essay "The Work of Art in the Age of Mechanical Reproduction" is brought to new and dizzying proportions. Adding to this is the fact that, where the material of the support-medium of film was once vulnerable and perishable, today's digital negatives - saved on laptops, memory cards, or the cloud - allow for the technical reproduction, described by Benjamin, to continue potentially ad infinitum, as photographs that had been damaged could be easily replaced by a new copy whenever desired.

On the subject of arrested motion and photography's ability to freeze an instant in time, Machado draws attention to the fact that this feature is originally inherited

${ }^{6}$ The term film refers to the photographic film of cameras, which is later processed to create the negative that will be printed. 
from figurative painting. However, in the case of painting, the moment portrayed in the image "is always that ideal and privileged time, filled with meaning and intention"7 (Machado, 2015, p. 52). The moment captured in photographs, by contrast, "is always this thoughtless and random time, this hundredth of a second without control, in which chance cannot be entirely abolished by an intention" (p. 52) ${ }^{8}$. In this way, photography always implies some measure of unpredictability. Yet Machado also stresses that "this single fragment of time, chosen by chance to be frozen in the photo, is also composed of countless other instants that the shutter is still incapable of distinguishing" (p. 54) ${ }^{9}$. Consequently, to the author, photographs are a condensation of countless instants, increasing the level of unpredictability concerning the instant that will actually appear in the final shot, an uncertainty that is not likely to be applied to figurative paintings.

As previewed, ekphraseis inspired by painting and by photography are likely to share many of the same basic principles, such as its bi-dimensionality, framing and point of view. For instance, some excerpts from Baume's novel present certain photographic features, most notably concerning the framing, the choice of photographic paper, and some aspects of the image itself. Other ekphrastic passages tend to focus on the object photographed, the composition of the scene or the identification of something worth being captured. Meanwhile, the depiction of the time occupied with the creative process is one of the main differences between ekphraseis inspired by photographs and the ones inspired by paintings. To fully understand the other differences between these two types of ekphraseis, it is relevant to perceive the nuances in each conception process from beginning to end.

When analysing elsewhere ${ }^{10}$ the ekphrastic descriptions of Vermeer's paintings in the novel Girl with a Pearl Earring ${ }^{11}$, three categories were proposed: (a) postwork ekphrasis, (b) pre-work ekphrastic moments, and (c) ekphrasis of works in progress (Vieira, 2011, pp. 16-21). The first category concerns specific media products, as when characters bring about existing paintings, whereas the second

7 Original text: "é sempre aquele tempo ideal e privilegiado, pleno de sentido e intenção" (Machado, 2015, p. 52).

8 Original text: "é sempre esse tempo impensado e aleatório, esse centésimo de segundo destituído de controle, em que o acaso não pode ser inteiramente abolido por uma intenção" (Machado, 2015, p. 52).

9 Original text: "esse único fragmento temporal que o acaso escolheu para congelar na foto é também ele composto por outros instantes que o obturador, todavia, não sabe distinguir" (Machado, 2015, p. 54).

${ }_{10}$ See Vieira (2011).

11 Written by Tracy Chevalier and published in 1999, the novel narrates the story of the fictional character Griet, a young Dutch protestant sent to work as a maid in the house of Johannes Vermeer. Throughout the novel, Griet becomes an assistant to the painter, culminating in her posing for the eponymous painting, Girl with a Pearl Earring (1665-1667). 
one refers to the creative process portrayed in ekphrastic passages before the work has actually been started, such as when the novel's characters discuss what the next commissioned paintings should be and what pictorial elements are to be included. Finally, the third category invokes ekphraseis that take place while the work is still under preparation, for instance when the two main protagonists, master and muse, negotiate the composition of the homonymous painting during the course of its execution. Such categorization has provided comprehension on the depiction of each process of conception of an artwork through ekphrastic passages. The mentioned categories were therefore borrowed for the investigation of ekphraseis inspired by photography in the novel A Line Made by Walking.

\section{Behind the shutter}

As previously mentioned, the capability of arrested motion, indexicality, framing, aspects related to the mechanical device and the chemical processes of fixing and printing images are some of the intrinsic features of photography, as enhanced by the following ekphrastic passage:

The last photograph is easy; I know which box it belongs in as soon as I turn it over. My
grandmother from the breastbone up, a jaunty regimental hat pinned at an angle to her sensible
hairdo.
Here is London at the start of the Second World War; the day she entered the Women's Royal
Naval Service. She is nineteen and still smiles with her teeth showing. By the end of the war,
most of the ones in the front rows had been knocked out: not by a bomb but a car accident - an
ambulance which crashed into a crater. This is a fact that has proved helpful to me in the sorting
of the muddled photographs. Some of those without a date scribbled on the back can be dated
by whether or not my grandmother has opened her mouth to smile.
How beautiful she looks, but then everyone always says that about old photographs; it can't
possibly be that people were uniformly better looking in the past, but that grainy monochrome is
more generally flattering than crystalline technicolour, and because having your portrait taken
was uncommon enough for people to bother dressing their best. Combing their hair just so,
striking an elegant pose.
I place the photo in its place. I pause for a moment of silent appreciation: my grandmother's
radiant yet under-celebrated life [emphasis added] (Baume, 2017, pp. 251-252).

Framed by explicit mentions to "photography" and "photo" the ekphrasis is filled with specific details regarding it as media technology, such as the "grainy monochrome" resultant from the type of device available to take portraits during the Second World War, in comparison to the "crystalline technicolour" of contemporary devices. From this excerpt, it is possible to observe how, isolated from the creative process, the category of post-work ekphrasis of excerpts inspired by photography is quite similar to the one regarding paintings. Apart from the differences stemming from the specificities of each medium (such as the way a painting can be constructed in front of the reader's eyes, playing with the mixing of colours and emotions displayed on the canvas), the two share many important 
features, such as their bidimensional nature, the importance of framing and light, point of view, and the composition of scenes. Additionally, the possibility of tracing the time period when the photo was taken relates to the indexical connection between photography and reality that is enabled by the presence of elements related to specific time periods that may be grasped only by means of specific background information - in this case, Frankie's grandmother's smile.

However, as announced, the focus of our analysis is Frankie's photographic series of animal corpses found in the surroundings of her grandmother's house in Ireland, as when she finds a mouse in an empty basin in her backyard. Her eyes immediately frame it within a square, as she will later do with her camera. She believes the framed image is her best photo so far:

There is something floating on the surface of the rainwater. I lean in and my face appears reflected in the green, and square in the green of my face, a mouse.

Floating on his belly, paws and tail extended. Ears inflated, eyes scrunched, nose submerged, whiskers pencilling frail lines through the green, a perfect drawing.

$[\ldots]$

I picture the mouse trying to swim, to scrabble back out. Slipping down the sides, a spider in a bathtub. Beneath the surface, the pads of her paws are pale and bald like palms of tiny hands. Her back legs are splayed as if she had been kicking at the instant her heart stopped. As if, in the instant which came before the stopping of her heart, she learned to swim, a second too late. $[\ldots]$

I fetch my camera anyway; she makes my most impeccable picture so far [emphasis added] (Baume, 2017, pp. 128-129).

The emphasized terms are related to the main features of photography, as evinced by the choice of the verb "picture" instead of "imagine", and the ability to recreate the moments before the mouse's death. Also, the presence of the camera at the end of the quote recalls the discussion regarding the distance the device imposes between photographer and the photographed subject, stressing even more Frankie's lethargy. Her first reaction to the dead mouse is to fetch a camera to capture the moment, distancing herself from that piece of reality.

In accordance with her own self-imposed rules for the project, the ekphrastic passage reveals how Frankie does not intervene or re-arrange the scene in any way. Photography's features are reinforced in order to present the object to the reader "as if"12 the tableau were already a photo, even though the actual photograph has yet to be taken. The narrator presents the object to be photographed in such a way that it already resembles a photo, her eyes functioning as the lenses of a camera, focusing on a random image that she later decides is worth being photographed.

12 The "as if" character is defined by Rajewsky (2005) as a form of intermedial reference, by which one medium creates an illusion of being another one by borrowing or evoking its medial specificities (p. 55). 
Photography's creative process is likely to happen well before the photo is actually "taken", in the aforementioned pre-work ekphrastic moments. This process is of two types, the first being when photographers exercise their photographic vision, randomly finding scenes and moments worth being recorded, as described by Barthes. By contrast, in the second type, the photographer carefully composes the scene he or she wishes to capture and dictates the way in which the subject is to be posed - all in view of achieving the specific pre-conceived effect the artist had in mind. Despite this division, a pre-work ekphrasis may focus more on the photographed subject/object, the composition of the scene, or the identification of an image worth capturing. However, this type of ekphrasis is likely to carry aspects of the work-in-progress category as well. As when Frankie breaks her own rules by consciously waiting for a rook to die so that she can take its photo. The creative process of the photographer interfering in the scene evidences the way the image is created before the photo is actually taken as:

The only surface which seems to hold [the droplets] is the rook's broken wing. His outstretched feathers are electric black. The drops sit like diamanté just for a second before dripping on, or being replenished and merging into fatter jewels, quivering. Up close, I see that beneath his broken wing, the rook is struggling to draw breath. He opens an eye and his pupil swivels around and registers me. His hindered breathing quickens but he does not caw; he does not shift. He's lying on a shallow heap of straw, the yellow and the black in bold contrast.

I climb back into the driver's seat, but I don't start the engine. I'm not allowed to photograph things which are not dead. And so, I must wait. [...] After a quarter of an hour, I get out and check the rook. He is still breathing, slower now. Again I go back to the car.

[...]

My hands have stopped shaking and the rook is dead. Or at least, I tell myself he's dead. In the spool of light cast from my headlamps, I don't look too closely. I'm tired and hungry and don't care about my own rules anymore. I just want my picture and to be gone [emphasis added] (Baume, 2017, pp. 139-141).

After hours parked by the side of the road, she decides that the rook is lifeless enough for her purposes, whether or not it is truly dead. Frankie's decision of waiting for it to die plays with the notion of Death which Barthes regards as the eidos of photographs, the intention to be looked for in it. In a way, this relation might be considered a reflection of her own motivations to start the series on dead animals, since she believed she was being slowly killed by the universe. Once again, the word choice in the excerpt reinforces the connection between Frankie's gaze and the medial traces of photography, as evinced by the use of "up close" to draw attention to a detail. She demonstrates the sensibility to shades of colours and contrast expected from a professional photographer.

Ignoring her own rules yet again, she removes a tin can from the face of a fox, thus altering the found scene: 


\begin{abstract}
And now, a fox. My birthday fox.
Pelt matted with dust, rear quarters indented with the mark of passing tyres. Hind legs twisted, paws flattened into novelty slippers. A gash in its side from which its entrails have slipped, already bloodless and writhing with flies.

And on its head, the tin can. Yellow label of Pedigree Chum, no eyeholes. So the tin-can fox couldn't see where it was going after all, nor what was approaching it.

$[\ldots]$

I pull the tin can off the fox's head. Restore its handsome face, and take my photograph [emphasis added] (Baume, 2017, pp. 163-165).
\end{abstract}

Differently from the previous excerpt concerning the rook, in which Frankie interferes by non-interfering while she waits for the animal's death, the episode of the fox refers to the creative process of finding the animal in the right time and directly interfering with her bare hands until she is satisfied with the composition of the scene. But similarly to previous episodes, when Frankie's eyes frame the image of the fox, she once again imagines the moment of its death, extrapolating the reality of the image itself based on indexical evidences on how it happened, namely the tin can in its head and the marks of passing tyres.

It is worth mentioning that the act of interference or non-interference during the initial creative process is also an important and frequently debated issue of photography. Sontag has argued that the act of taking a photograph is an event in itself, embedded with the right to interfere, invade or ignore what is happening, in order to create the intended visual effect. However, she also adds that "photographing is essentially an act of non-intervention [...] the person who is recording cannot intervene" (Sontag, 1977, p. 8). To Sontag, this does not mean, of course, that photographing is an act of merely passive observation, as it instigates whatever action that is happening to continue, sometimes independently of another's pain. The above-mentioned interest of maintaining things as they are may be related to the idea that, after taking a photograph, that small piece of reality is confined within the frame, untouched and unchanged. Hence, when Frankie decides to wait for the rook to die and to remove the tin can from the fox's head, she is simply practicing her right, as a photographer, to interfere directly or indirectly, by ignoring what is happening, on behalf of the aesthetics of her series.

Since photographs are taken by means of mechanical devices that take advantage of chemical processes, and alterations to the image during the camera's operation are minimal, ekphrastic moments portraying the creative process in a work in progress may overlap with the category of post-work ekphrasis. This is because photos may be edited after they are taken, using computer software like Photoshop or Adobe Lightroom. The photographer is able to manipulate the image in view of achieving a certain effect, for example by controlling its colour, contrast, brightness, saturation, and so on. An ekphrastic passage may therefore depict the photo both as it was taken and as it appears after editing, 
drawing attention to what the photographer wished to highlight or elide. This occurs when Frankie recounts plugging in her camera and downloading the photos to her laptop. She describes how

My robin looks angry, much angrier in reproduction than it appeared in life. Perhaps the Native Americans are right; perhaps the camera stole its spirit. I open my robin in Photoshop. I select Brightness/Contrast. I restore the vibrancy lost along with its spirit [emphasis added] (Baume, 2017, p. 17).

Frankie deliberately decides to attenuate the anger she sees in the photo of the robin. She does this by adulterating aspects related to light and contrast in order to achieve the desired vibrancy. This anger she notices in the robin might be related to the belief regarding cameras stealing spirits, almost as if the animal's spirit were angry for being imprisoned in the image. However, she again distances herself from the situation, deciding what needs to be altered to make the photograph more pleasant and to restore the spirit's vibrancy.

The novel also depicts the manipulation of the image as being motivated by instinct rather than any defined reason. Frankie narrates that "downloading the rook's picture, [she feels] compelled to adulterate the colour balance in Photoshop. [She fiddles] with the contrast until his feathers are unrealistically blue". Then she wonders, "why must I blue my crow [...] What does a blue crow mean?" [emphasis added] (Baume, 2017, p. 143). The photographer manipulates the image, even if she does not fully grasp her reasons for doing so.

By presenting the protagonist's aesthetic choices to the reader, Baume increases the understanding about the different stages of the creative process behind photographs. She draws attention to choices made bearing in mind the exact impact she wanted to make on a receiver, as well as to the intrinsic relation between Frankie and issues related to photography, such as the distance the camera adds between the photographer and the photographed reality, and photography's relation to death.

\section{Framing a (possible) closure}

In this article, we have discussed how photography evolved from a device used by painters, the camera obscura, to a mechanical device capable of fixing luminous information into photographic film by means of chemical processes. It is perhaps unsurprising, then, that the two media share many similarities. These include the decisional process of framing, by which the artist (whether painter or photographer) defines what is inside the picture/photo as worthy of being seen and relegates the rest to an invisible exterior, in accordance with his or her chosen perspective. Whereas the painting process lasts longer and allows for alterations during development, the photographic process of capturing an image, as depicted in A Line Made by Walking, is instantaneous and may allow 
alteration only during the post-editing phase, although the alterations in question (especially when performed via digital manipulation) may be considerable. These and other factors will affect the way the artist's creative process is depicted in ekphrastic passages inspired either by painting or by photography. The former affords more space to focus on how the image is slowly created, the materials chosen to compose the colours and the emotions of the artist while doing so, as well as the painter's motivations for the aesthetic choices made during the process. On the other hand, with photography, the creative process is better explored during pre- and post-work ekphrasis, in which the photographer faces a series of aesthetic choices: whether to interfere or not with the subject, choosing what to depict in the frame, as well as post-editing choices regarding colour, saturation, and contrast, all of which may be manipulated in view of a specific effect. Nevertheless, since the actual capturing of a photo lasts only an instant, the so-called work in progress category is the one that mostly distinguishes an ekphrasis inspired by photography.

\section{The final frame}

In sum, by borrowing parameters used for painting, it was possible to stroll through various photography's medial traits and the creative process involved in Frankie's project. By means of skilfully captured ekphrastic passages, it was possible to observe not only the ways in which the protagonist's aesthetic decisions influenced the photographed object, but also how the act of photographing may in fact interfere with reality, even by not directly interfering in the real world. While the self-isolated protagonist experiences the constant feeling of being slowly killed, photography provides her an extra layer of distance between her own self and the grotesqueness of a reality that is far beyond control. Frankie may be able to freeze an image in time as a certificate of existence, or even capture the spirit of an animal corpse. Nevertheless, death remains inevitable.

\section{References}

Baume, S. (2017). A Line Made by Walking. New York: Houghton Mifflin Harcourt Books.

Barthes, R. (1984). A Câmara Clara: Nota sobre a Fotografia (J. Castañon Guimarães, Trans.). Rio de Janeiro: Nova Fronteira.

Benjamin, W. (1936). The Work of Art in the Age of Mechanical Reproduction. Retrieved December 16, 2019, from http://www.marxists.org/reference/subject/philosophy/works/ge/benjamin. htm.

Bruhn, J. (2016). The Intermediality of Narrative Literature: Medialities Matter. London: Palgrave Macmillan.

Chevalier, T. (1999). Girl with a Pearl Earring. New York: Plume Printing.

Clüver, C. (2016). Ekphrasis and adaptation. In T. Leitch (Ed.), The Oxford Handbook of Adaptation Studies (pp. 459-477). New York: Oxford University Press.

Elleström, L. (2010). Media Borders, Multimodality and Intermediality. New York: Palgrave Macmillan. 
Fainguelernt, M. (2014). A câmara escura e a fotografia. Scientiarum Historia, 7. Retrieved December 16, 2019, from http://www.hcte.ufrj.br/downloads/sh/sh7/SH/trabalhos\%20orais\% 20completos/A-CAMERA-ESCURA-E-A-FOTOGRAFIA.pdf.

Heffernan, J. A. W. (1993). Museum of Words: The Poetics of Ekphrasis from Homer to Ashbery. Chicago: University of Chicago Press.

Krauss, R. (1977). Notes on the index: Seventies art in America. Part 2. October, 4, 58-67.

Machado, A. (2015). A Ilusão Especular: Uma Teoria da Fotografia. São Paulo: Gustavo Gili.

Rajewsky, I. (2005). Intermediality, intertextuality, and remediation: A literary perspective on intermediality. Intermédialités, 6, 43-64.

Sontag, S. (1977). On Photography. New York: Farrar, Straus and Giroux.

Vieira, M. (2011). Ekphrasis in "Girl with a Pearl Earring”. Scripta Uniandrade, 9(2), 11-29.

Vieira, M. (2017). Écfrase: De recurso retórico na Antiguidade a fenômeno midiático na contemporaneidade. Todas as Letras, 19(1), 45-57.

Webb, R. (2009). Ekphrasis, imagination and persuasion in ancient rhetorical theory and practice. Surrey: Ashgate. 